\section{(6) OPEN ACCESS}

\title{
Prognostic impact of p16 and PD-L1 expression in patients with oropharyngeal squamous cell carcinoma receiving a definitive treatment
}

\author{
Fumihiko Sato, ${ }^{1}$ Takeharu Ono, ${ }^{1}$ Akihiko Kawahara, ${ }^{2}$ Toshihiko Kawaguchi, ${ }^{1}$ \\ Hisaichiro Tanaka, ${ }^{1}$ Kazuhide Shimamatsu, ${ }^{3}$ Tatsuyuki Kakuma, ${ }^{4}$ Jun Akiba, ${ }^{2}$ \\ Hirohito Umeno, ${ }^{1}$ Hirohisa Yano ${ }^{5}$
}

\begin{abstract}
- Additional material is published online only. To view please visit the journal online (http://dx.doi.org/10.1136/ jclinpath-2019-205818)
\end{abstract}

'Department of OtolaryngologyHead and Neck Surgery, Kurume University School of Medicine, Kurume, Japan

${ }^{2}$ Department of Diagnostic Pathology, Kurume University Hospital, Kurume, Japan ${ }^{3}$ Department of Pathology, Omuta City Hospital, Omuta, Japan

${ }^{4}$ Biostatistics Center, Kurume University School of Medicine, Kurume, Japan

${ }^{5}$ Department of Pathology, Kurume University School of Medicine, Kurume, Japan

Correspondence to Dr Takeharu Ono, Department of Otolaryngology-Head and Neck Surgery, Kurume University School of Medicine, Kurume 830-0011, Japan; ono123@ med.kurume-u.ac.jp

Received 1 March 2019 Revised 6 April 2019 Accepted 10 April 2019 Published Online First 21 May 2019

\section{Check for updates}

(C) Author(s) (or their employer(s)) 2019. Re-use permitted under CC BY-NC. No commercial re-use. See rights and permissions. Published by BMJ.

\section{To cite: Sato $F$,}

Ono T, Kawahara A,

et al. J Clin Pathol

2019:72:542-549.

\begin{abstract}
Aims Limited information is available regarding the precise differences in the tumour immune microenvironment (TIM) of patients with human papilloma virus (HPV)-associated and non-HPVassociated oropharyngeal squamous cell carcinoma (OPSCC). Here, we retrospectively reviewed 137 patients with OPSCC treated with a definitive treatment to identify molecular relationships in the TIM.

Materials and methods We used immunohistochemical analysis to assess p 16 status, programmed death ligand 1 (PD-L1) level, and/or CD8 ${ }^{+}$ tumour-infiltrating lymphocyte (TIL) density, followed by prognostic evaluation of these immune-related parameters.
\end{abstract}

Results Multivariate analyses demonstrated that PD-L1 level on immune cells but not on tumour cells or CD8 ${ }^{+}$ TIL density was a significant predictive factor of diseasefree survival (DFS) and overall survival (OS). Additionally, subgroup analyses demonstrated that patients positive for p16 and PD-L1 expression on immune cells had favourable DFS and OS, whereas patients negative for p16 and PD-L1 expression on immune cells showed worse DFS and OS.

Conclusions We demonstrated that PD-L1 expression on immune cells but not tumour cells might represent a useful prognostic biomarker in patients with OPSCC receiving a definitive treatment. We propose that a coassessment of $\mathrm{p} 16$ and PD-L1 expression on immune cells would have greater prognostic potential compared with evaluation of each factor alone in patients with OPSCC.

\section{INTRODUCTION}

Therapeutic response (radiotherapy or chemotherapy) and the prognosis of patients with human papilloma virus (HPV)-associated oropharyngeal squamous cell carcinoma (OPSCC) are more favourable compared with those in patients with non-HPV-associated OPSCC. Overexpression of p16, a cyclin-dependent kinase inhibitor, is closely related to HPV-associated OPSCC and an independent prognostic biomarker in patients with OPSCC. $^{12}$

Recent studies suggest that the tumour immune microenvironment (TIM) plays an important role in carcinogenesis and tumour regression or progression. Additionally, $\mathrm{CD} 8^{+}$tumour infiltrating lymphocytes (TILs), which exert cytotoxic effects, are the major immune cells that act against tumour cells, with their higher density associated with a favourable prognosis in patients with head and neck cancer. ${ }^{34}$ A recent study reported that programmed death-1 (PD-1), a receptor expressed on the surface of $\mathrm{T}$ cells, exhausts effector $\mathrm{T}$ cells by binding to programmed death ligand 1 (PD-L1) on tumour cells. ${ }^{5}$ Interestingly, patients with oropharyngeal cancer and elevated PD-L1 expression have a favourable prognosis relative to patients with low PD-L1 expression. ${ }^{6}$ Moreover, HPV infection, which upregulates PD-L1 expression on tumour cells, has been associated with favourable prognosis in patients with OPSCC; however, little is known about the precise differences in the TIM of patients with HPV-associated and non-HPV-associated OPSCC. Furthermore, associations between expression of PD-L1 on tumour cells and immune cells in stroma, p16 status, and TILs with OPSCC outcome have not been investigated. Therefore, we investigated the prognostic value of PD-L1 expression on tumour cells or immune cells, including $\mathrm{T}$ lymphocytes, macrophages, and dendritic cells, ${ }^{7}$ and CD8 ${ }^{+}$ TIL density, in patients with OPSCC.

\section{MATERIALS AND METHODS \\ Patients}

We retrospectively screened consecutive patients diagnosed with OPSCC at Kurume University Hospital (Kurume, Japan) between 2000 and 2016. The inclusion criteria were as follows: pathological diagnosis of OPSCC; treated with surgery, chemoradiotherapy (CRT) or radiotherapy (RT); and the availability of adequate histological specimens containing tumour cells.

This study complied with the ethical guidelines outlined by the Declaration of Helsinki, as well as the institutional guidelines on human experimentation by the Ethical Committee of Kurume University. Informed consent was obtained from each patient.

\section{Immunohistochemical analysis}

Paraffin-embedded tissue was cut to $4 \mu \mathrm{m}$ samples, examined on coated glass sides, and labelled with the following antibodies using the Bond-III autostainer (Leica Microsystems, Newcastle, UK) and BenchMark ULTRA (Ventana Automated Systems, 
Tucson, Arizona, USA). Primary antibodies (with dilutions) were as follows: PD-L1 (1:100; clone E1L3N; Cell Signalling Technology, Danvers, Massachusetts, USA), CD8 (1:200; clone 4B11; Leica Microsystems) and p16 (ready to use; clone 16P04; Ventana Automated Systems). Immunostaining with CD8 and PD-L1 was performed using the same fully automated Bond-III system (Leica Microsystems) with onboard heat-induced antigen retrieval performed using epitope-retrieval solution-2 (in EDTAbased buffer ( $\mathrm{pH}$ 9.0); Leica Microsystems) for $10 \mathrm{~min}$ at $99^{\circ} \mathrm{C}$, followed by incubation with each antibody for $30 \mathrm{~min}$ at room temperature. For p16, the BenchMark ULTRA system (Ventana Automated Systems) was used. Briefly, each slide was heat-treated using ULTRA cell-conditioning-1 retrieval solution (Ventana Automated Systems) for $60 \mathrm{~min}$ at $95^{\circ} \mathrm{C}$, followed by incubation with the p16 antibody for $32 \mathrm{~min}$ at $37^{\circ} \mathrm{C}$. This automated system used the streptavidin-biotin complex with 3,3'-diaminobenzidine as the chromogen (Ventana UltraVIEW DAB detection kit; Ventana Automated Systems).

All IHC results were evaluated by two pathologists (AK and JA) who were unaware of patient conditions. Any disagreement between pathologists was resolved by a joint review to obtain a single consensus category.

p16 expression was considered positive if more than $70 \%$ of tumour cells showed moderate or strong and diffuse nuclear staining. ${ }^{8}$ PD-L1 expression on tumour cells (TC-PD-L1) was classified as follows: less than $1 \%$, from $1 \%$ to $4 \%$; and $5 \%$. or higher. PD-L1 expression of 5\% or higher was considered positive, as previously reported. ${ }^{679}$ Additionally, PD-L1 expression on immune cells in stroma (IC-PD-L1) surrounding the tumour was classified according to the same percentages used for tumour cells, with positivity considered at $5 \%$ or higher. ${ }^{7}{ }^{10}$ Furthermore, $\mathrm{CD} 8^{+}$TILs were counted in five high-power fields of view (magnification: $400 \times$ ), and these averages were assessed. The cut-off values for the number of $\mathrm{CD}^{+}$TILs are presented as medians.

\section{Statistical analyses}

We evaluated whether variables, including TC-PD-L1 or IC-PD-L1 level, were associated with the survival of patients with OPSCC treated with a definitive treatment. Correlations between p16 expression on tumour cells, TC-PD-L1 level, or IC-PD-L1 level and patient characteristics were analysed using the Fisher's exact test for categorical variables. Correlations between p16 expression, TC-PD-L1 level, or IC-PD-L1 level and $\mathrm{CD} 8^{+}$TIL density were analysed using the Wilcoxon's test for continuous variables. Disease-free survival (DFS) and overall survival (OS) were calculated from the date of initiating treatment to tumour relapse (locoregional recurrence, distant metastasis, or both) or death, respectively. Kaplan-Meier analysis was used to assess patient survival, and a log-rank test was used to evaluate significant differences between and among two or four groups, respectively. Clinical and pathological variables associated with a $\mathrm{p}$ value less than 0.05 according to univariate analysis were subjected to multivariate analysis using a Cox proportional hazard models. All tests were two sided, and a $\mathrm{p}$ value less than 0.05 indicated a statistically significant difference. Statistical analyses were performed using JMP (v.13; SAS Institute, Cary, North Carolina, USA).

\section{RESULTS}

\section{Patient characteristics}

The clinical characteristics of the 137 patients included in this study are presented in table 1 . The median age of the patients at diagnosis was 63 years (range 36-83 years) and included 113 men (82.5\%). Performance status (PS) assessment indicated that $135(98.5 \%)$ and $2(1.5 \%)$ patients were PS (0) and PS (1), respectively. The median follow-up period was 37 months (range 17.6-219.3 months), and smoking and alcohol consumption was noted by $98(71.5 \%)$ and $90(65.7 \%)$ patients, respectively. Tumour histology was classified as well differentiated (52 patients), moderately differentiated (64 patients) or poorly differentiated (21 patients). The anatomical subsites were classified as lateral wall (77 patients), anterior wall (39 patients), posterior wall (10 patients) and superior wall (11 patients). In accordance with the system adopted by the Union for International Cancer Control TNM Classification of Malignant Tumours 7th Edition, ${ }^{11} 10$ (7.3\%), 21 (15.3\%), 27 (19.7\%) and $79(57.7 \%)$ patients exhibited stage I, II, III or IV disease at the time of diagnosis, respectively, with 53 patients $(38.7 \%)$ receiving surgical treatment, $81(59.1 \%)$ receiving concurrent cisplatin-based CRT and $3(2.2 \%)$ receiving RT.

\section{P16 or PD-L1 expression and CD8+ TIL density}

We restricted our immunohistochemical (IHC) analysis to p16 or PD-L1 expression and CD $8^{+}$TIL density due to limited tissue availability. Figure 1 shows the representative staining patterns of PD-L1 and CD8 in the tumour specimens. PD-L1 expression was observed in the membrane, cytoplasm or both in tumour cells and/or stromal lymphocytes.

Regarding p16 expression in tumour cells, positive and negative staining was detected in 59 (43.1\%) and 78 (56.9\%) patients, respectively (table 1 ). There were 81 patients $(59.1 \%)$ positive for TC-PD-L1 ( $\geq 5 \%)$ and $83(60.6 \%)$ positive for IC-PD-L1 in stroma. The median of CD ${ }^{+}$TILs was 18.6 (range 0-138.4), therefore this was used to distinguish between patients with high and low TIL density.

\section{Correlation between p16 or PD-L1 expression and patient characteristics}

The relationships between p16 expression, TC-PD-L1 level or IC-PD-L1 level and patient demographics are presented in table 1 . We detected significant correlations between p16 expression and smoking status $(p=0.019)$, alcohol status $(p=0.001)$, tumour differentiation $(p=0.007), c N$ stage $(p=0.001)$ and cStage $(\mathrm{p}<0.001)$.

Regarding TC-PD-L1, significant correlations with TC-PD-L1 expression were shown for sex $(p=0.039)$, tumour differentiation $(p=0.008)$, cN stage $(p=0.038)$, cStage $(p=0.012)$ and definitive treatment $(p=0.032)$. Additionally, patients positive for IC-PD-L1 showed significant correlations with smoking status $(p=0.016)$, alcohol status $(p=0.007)$, and tumour differentiation $(\mathrm{P}=0.008)$.

\section{Correlations between $\mathrm{p} 16$ expression and PD-L1 expression and CD8 ${ }^{+}$TIL density and TC-PD-L1 level and CD8 ${ }^{+}$TIL density}

We identified significant positive correlations between p16 expression and TC-PD-L1 level $(\mathrm{p}<0.001)$, IC-PD-L1 level $(\mathrm{p}<0.001)$ and $\mathrm{CD} 8^{+}$TIL density $(\mathrm{p}<0.001)$ (figure $\left.2 \mathrm{~A}-\mathrm{C}\right)$. Additionally, we found a significant correlation between TC-PD-L1 level and CD8 ${ }^{+}$TIL density $(p<0.001)$ (figure 2D).

\section{TIM classification}

We classified TIM into four types based on the combination of TC-PD-L1 and CD8 ${ }^{+}$TIL density (type I: TC-PD-L1 ${ }^{+/ \text {high }} \mathrm{CD} 8^{+}$ TIL density; type II: TC-PD-L1 ${ }^{- \text {llow }} \mathrm{CD} 8^{+}$TIL density; type III: TC-PD-L1 ${ }^{+/ \text {low }} \mathrm{CD}^{+}$TIL density; and type IV: TC-PD-L1 ${ }^{-}$ 
Table 1 Relationships between p16 or PD-L1 expression and patient characteristics

\begin{tabular}{|c|c|c|c|c|c|c|c|c|c|c|}
\hline \multirow[b]{2}{*}{ Characteristics } & \multirow{2}{*}{$\begin{array}{l}\text { No of patients } \\
(\%)\end{array}$} & \multicolumn{2}{|l|}{$\mathrm{p} 16$} & \multirow[b]{2}{*}{$P$ value } & \multicolumn{2}{|l|}{ TC-PD-L1 } & \multirow[b]{2}{*}{$P$ value } & \multicolumn{2}{|l|}{ IC-PD-L1 } & \multirow[b]{2}{*}{$P$ value } \\
\hline & & Negative (\%) & Positive (\%) & & $<5 \%(\%)$ & $\geq 5 \%(\%)$ & & $<5 \%(\%)$ & $\geq 5 \%(\%)$ & \\
\hline & 137 & $78(56.9)$ & $59(43.1)$ & & $56(40.9)$ & $81(59.1)$ & & $54(39.4)$ & $83(60.6)$ & \\
\hline Age (years) & & & & 0.083 & & & 0.728 & & & 0.728 \\
\hline$<63$ & $62(45.3)$ & 30 & 32 & & 24 & 38 & & 22 & 40 & \\
\hline$\geq 63$ & 75 (54.7) & 48 & 27 & & 32 & 43 & & 32 & 43 & \\
\hline Sex & & & & 0.5 & & & $0.039 *$ & & & 0.358 \\
\hline Male & $113(82.5)$ & 66 & 47 & & 51 & 62 & & 47 & 66 & \\
\hline Female & $24(17.5)$ & 12 & 12 & & 5 & 19 & & 7 & 17 & \\
\hline Smoking status & & & & $0.019^{*}$ & & & 0.201 & & & ${ }^{*} 0.016$ \\
\hline No & $33(24.1)$ & 14 & 19 & & 10 & 23 & & 8 & 25 & \\
\hline Yes & 98 (71.5) & 58 & 40 & & 42 & 56 & & 41 & 57 & \\
\hline Unknown & $6(4.4)$ & 6 & 0 & & 4 & 2 & & 5 & 1 & \\
\hline Alcohol status & & & & $0.001^{*}$ & & & 0.07 & & & ${ }^{*} 0.007$ \\
\hline No & $39(28.5)$ & 15 & 24 & & 12 & 27 & & 11 & 28 & \\
\hline Yes & $90(65.7)$ & 55 & 35 & & 38 & 52 & & 36 & 54 & \\
\hline Unknown & $8(5.8)$ & 8 & 0 & & 6 & 2 & & 7 & 1 & \\
\hline Differentiation & & & & $0.007^{*}$ & & & $0.008^{*}$ & & & ${ }^{*} 0.008$ \\
\hline Well or moderately & $116(84.7)$ & 72 & 44 & & 53 & 63 & & 52 & 64 & \\
\hline Poorly & $21(15.3)$ & 6 & 15 & & 3 & 18 & & 2 & 19 & \\
\hline cT stage & & & & 0.605 & & & 1 & & & 0.861 \\
\hline $\mathrm{T} 1$ or T2 & $78(56.9)$ & 46 & 32 & & 32 & 46 & & 30 & 48 & \\
\hline T3 or T4 & $59(43.1)$ & 32 & 27 & & 24 & 35 & & 24 & 35 & \\
\hline cN stage & & & & $0.001^{*}$ & & & $0.038^{*}$ & & & 0.861 \\
\hline N0 or N1 & $61(44.5)$ & 44 & 17 & & 31 & 30 & & 25 & 36 & \\
\hline N2 or N3 & $76(55.5)$ & 34 & 42 & & 25 & 51 & & 29 & 47 & \\
\hline cStage & & & & $<0.001^{*}$ & & & $0.012^{*}$ & & & 0.532 \\
\hline | or II & 31 (22.6) & 27 & 4 & & 19 & 12 & & 14 & 17 & \\
\hline III or IV & $106(77.4)$ & 51 & 55 & & 37 & 69 & & 40 & 66 & \\
\hline Definitive treatment & & & & 0.216 & & & $0.032^{*}$ & & & 0.477 \\
\hline Surgery & $53(38.7)$ & 34 & 19 & & 28 & 25 & & 23 & 30 & \\
\hline CRT or RT & $84(61.3)$ & 44 & 40 & & 28 & 56 & & 31 & 53 & \\
\hline
\end{tabular}

CRT, chemoradiotherapy; IC-PD-L1, programmed death ligand 1 on immune cells; RT, radiotherapy; TC-PD-L1, programmed death ligand 1 on tumour cells.

${ }^{\text {high }} \mathrm{CD}^{+}$TIL density) (figure 2D), as previously reported. ${ }^{12} 13$ Types I, II, III and IV were found in 53 (38.7\%), 39 (28.5\%), $28(20.4 \%)$ and 17 patients (12.4\%), respectively. Notably, 40 (67.8\%), 5 (8.5\%), $9(15.3 \%)$ and $5(8.5 \%)$ patients with $\mathrm{p} 16^{+}$ disease were classified as having types I, II, III and IV TIMs, respectively, whereas $13(16.7 \%), 34(43.6 \%), 19(24.4 \%)$ and $12(15.4 \%)$ patients with $\mathrm{p} 16^{-}$disease were classified as having types I, II, III and IV TIMs, respectively. Furthermore, we found a significant difference among TIM types in patients with $\mathrm{p} 16^{+}$ and $\mathrm{p} 16^{-}$disease $(\mathrm{p}<0.001)$.

\section{Survival analysis}

We then performed a Kaplan-Meier analysis to evaluate whether TC-PD-L1 or IC-PD-L1 level and CD8 ${ }^{+}$TIL density were associated with DFS or OS (figure 3). The results showed that the TC-PD-L1 level was not significantly correlated with DFS (positive vs negative; median survival time (MST) not reached vs 58.3 months; $\mathrm{p}=0.078$ ), whereas OS was significantly correlated (positive vs negative; MST not reached vs 89.3 months; $\mathrm{p}=0.035$ ) (figure $3 \mathrm{~A}, \mathrm{~B}$ ). By contrast, patients with a positive IC-PD-L1 level experienced significantly longer DFS (positive vs negative; MST not reached vs 38.2 months; $p=0.007$ ) and OS (positive vs negative; MST not reached vs 52.0 months; $\mathrm{p}<0.001$ ) (figure $3 \mathrm{C}, \mathrm{D}$ ). Additionally, we found that $\mathrm{CD} 8^{+} \mathrm{TIL}$ density was significantly correlated with DFS (high vs low; MST not reached vs 46.5 months; $\mathrm{p}=0.025$ ) and OS (high vs low; MST 152.2 vs 77.9 months; $\mathrm{p}=0.012$ ) (figure 3E, F).

Univariate analyses indicated that IC-PD-L1 level and CD ${ }^{+}$ TIL density were significant predictive factors of DFS (HR $0.50,95 \%$ CI: 0.29 to $0.83 ; \mathrm{p}=0.008$; and $\mathrm{HR} 0.54,95 \% \mathrm{CI}$ 0.32 to $0.92 ; \mathrm{p}=0.024$, respectively). Additionally, TC-PD-L1 level, IC-PD-L1 level and CD8 status were significant predictive factors of OS (HR $0.54,95 \%$ CI 0.31 to $0.96 ; p=0.036$; HR $0.36,95 \%$ CI 0.20 to 0.65 ; p $<0.001$; and HR $0.47,95 \%$ CI 0.25 to $0.84 ; \mathrm{p}=0.011$, respectively) (table 2). Furthermore, multivariate analyses revealed IC-PD-L1 level is an independent and significant predictive factor of DFS (HR 0.56, 95\% CI 0.33 to $0.96 ; \mathrm{p}=0.036$ ) and OS (HR $0.43,95 \%$ CI 0.22 to 0.82 ; $\mathrm{p}=0.010)($ table 2$)$.

\section{Correlation between survival and p16 status combined with PD-L1 expression on immune cells}

We then performed analyses to determine whether the combination of p16 expression and IC-PD-L1 level was predictive of patient prognosis. We divided patients into four subgroups according to p16 expression and IC-PD-L1 level subgroups

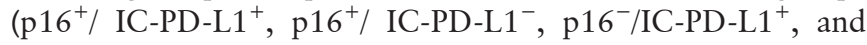
$\left.\mathrm{p} 16^{-} / \mathrm{IC}-\mathrm{PD}-\mathrm{L}^{-}\right)$. The results of Kaplan-Meier analyses of DFS and OS in the four groups are presented in figure 4. 

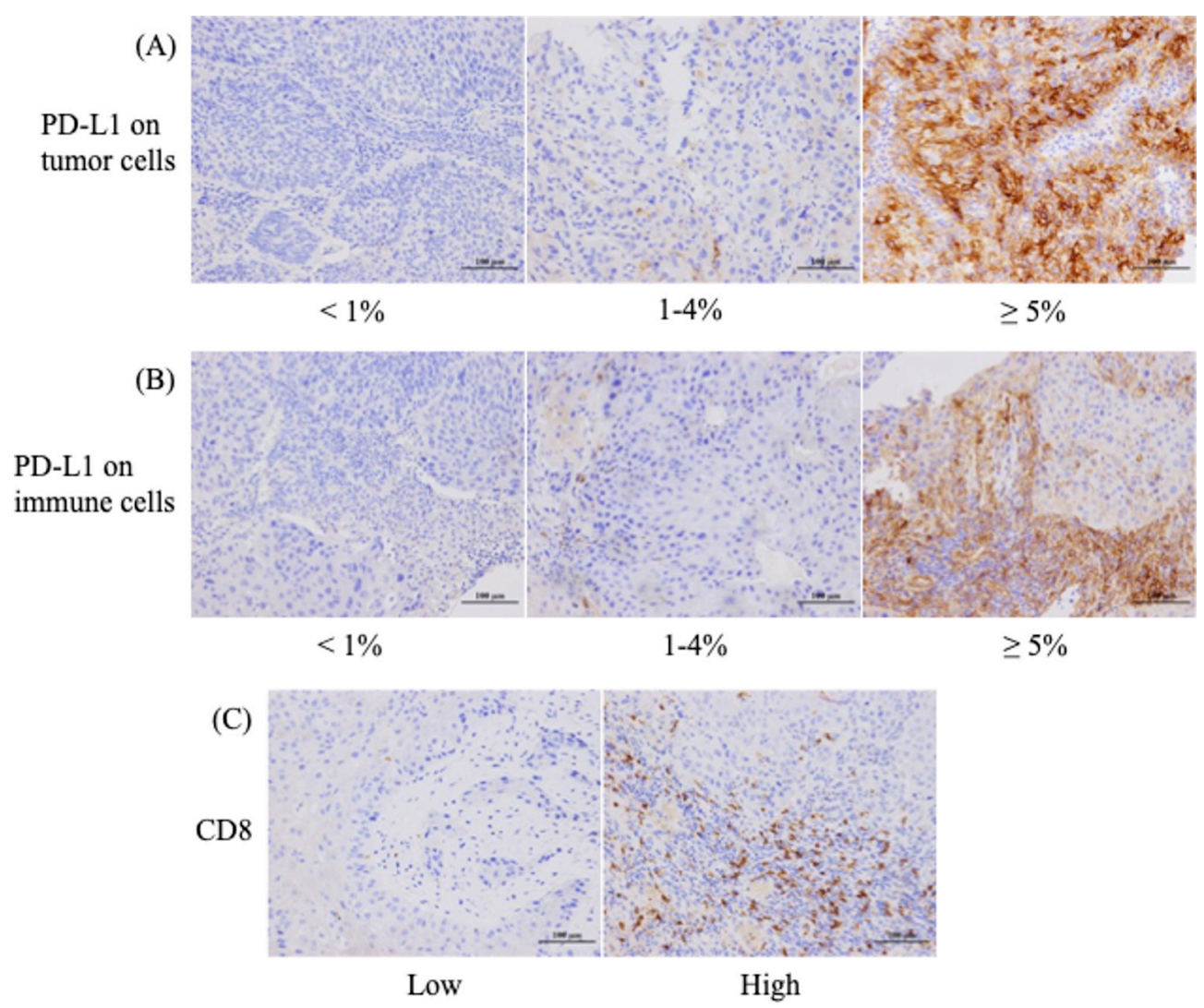

Figure 1 Immunohistochemical (IHC) staining patterns for programmed death ligand 1 (PD-L1) on tumour and immune cells and CD8 ${ }^{+}$tumourinfiltrating lymphocyte density in patients with oropharyngeal squamous cell carcinoma. (A) Representative examples of patients whose tumour proportion scores were classified as less than $1 \%$, from $1 \%$ to $4 \%$, and $5 \%$ or higher for the membrane expression of PD-L1. (B) Different PD-L1 levels on immune cells in the stroma. (C) High or low IHC staining patterns for CD8.
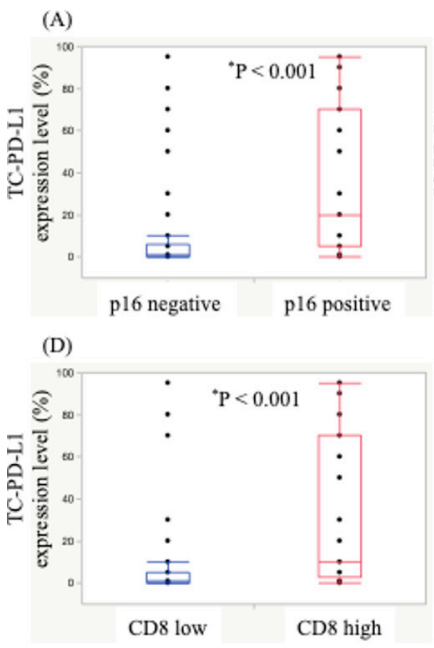

(B)

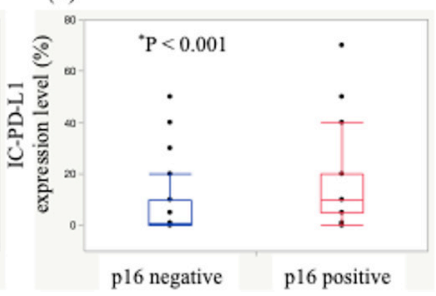

(E)

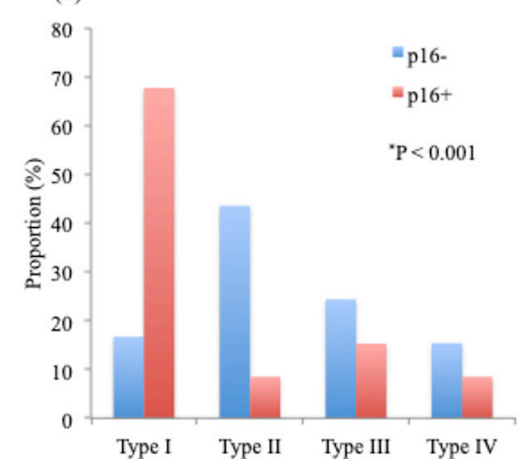

Figure 2 Correlations between p16 status, programmed death ligand 1 expression on tumour cells (TC-PD-L1), programmed death ligand 1 expression on immune cells (IC-PD-L1) and CD8 ${ }^{+}$tumour-infiltrated lymphocyte density (TIL). (A) TC-PD-L1 expression level according to p16 status. (B) IC-PD-L1 expression level according to p16 status. (C) CD8 ${ }^{+}$TIL density according to p16 status. (D) TC-PD-L1 expression level according to high or low CD8 ${ }^{+}$TIL density. (E) Tumour immune microenvironment types classified by TC-PD-L1 level and CD8 ${ }^{+}$TIL density according to p16 status. Significant differences were evaluated using the Wilcoxon and the Fisher's exact tests. 

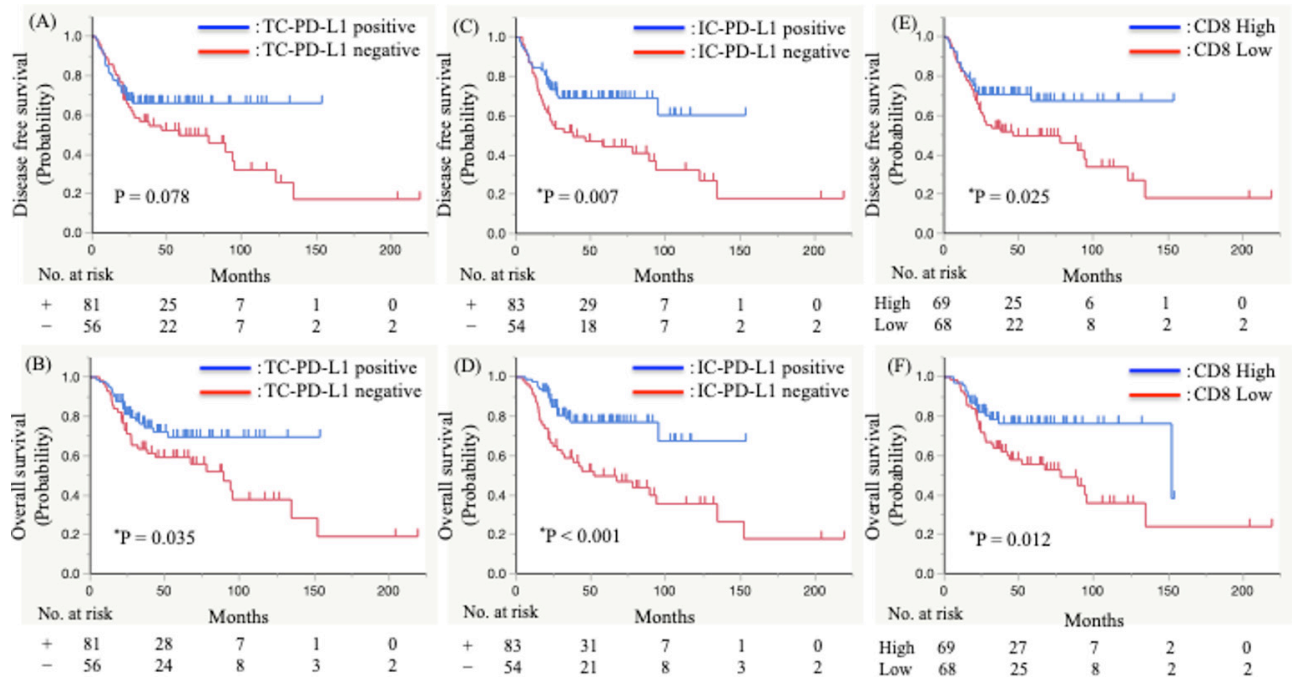

Figure 3 Kaplan-Meier analysis of the disease-free survival and overall survival of patients with advanced oropharyngeal squamous cell carcinoma. $(\mathrm{A}, \mathrm{B})$ Programmed death ligand 1 (PD-L1) ${ }^{+}$or PD-L1- tumour cells, $(\mathrm{C}, \mathrm{D}) \mathrm{PD}-\mathrm{L} 1^{+}$or PD-L1- immune cells in the stroma, and $(\mathrm{E}, \mathrm{F})$ high or low $\mathrm{CD} 8^{+}$ tumour-infiltrated lymphocyte density. Significant differences were evaluated using a log-rank test.

The median DFS was not reached in the $\mathrm{p} 16^{+} / \mathrm{IC}-\mathrm{PD}-\mathrm{L} 1^{+}$ group, 89.3 months in the $\mathrm{p}^{+} / 6^{+}$IC-PD-L1 ${ }^{-}$group, 27.3 months in the $\mathrm{p}^{-} 6^{-} / \mathrm{IC}-\mathrm{PD}-\mathrm{L1}^{+}$group, and 26.1 months in the $\mathrm{p} 16^{-} /$IC-PD-L1 ${ }^{-}$group $(\mathrm{p}<0.001)$ (figure $\left.4 \mathrm{~A}\right)$. Additionally, the $\mathrm{p} 16^{+} / \mathrm{IC}-\mathrm{PD}-\mathrm{L} 1^{+}$group displayed a significantly better DFS than the $\mathrm{p} 16^{-} / \mathrm{IC}-\mathrm{PD}-\mathrm{L} 1^{+}$group (HR $0.20,95 \%$ CI 0.07 to $0.46 ; \mathrm{p}<0.001$ ) and the $\mathrm{p} 16^{-} / \mathrm{IC}-\mathrm{PD}-\mathrm{L} 1^{-}$group (HR 0.17 , $95 \%$ CI 0.06 to $0.38 ; \mathrm{p}<0.001)$. Moreover, although not statistically significant, we observed that the $\mathrm{p} 16^{+} / \mathrm{IC}-\mathrm{PD}-\mathrm{L} 1^{+}$group displayed a more favourable DFS than the $\mathrm{p} 16^{+} / \mathrm{IC}_{\mathrm{P}} \mathrm{PD}-\mathrm{L} 1^{-}$ group (HR 0.35, 95\% CI 0.10 to 1.35 ; $\mathrm{p}=0.119$ ).

The median OS was not reached in the $\mathrm{p} 16^{+} / \mathrm{IC}_{\mathrm{I}} \mathrm{PD}-\mathrm{L} 1^{+}$ group, 89.3 months in the $16^{+} / \mathrm{IC}-\mathrm{PD}-\mathrm{L} 1^{-}$group, 95.1 months in the $\mathrm{p} 16^{-} / \mathrm{IC}-\mathrm{PD}-\mathrm{L}^{+}$group, and 41.0 months in the $\mathrm{p} 16^{-} /$ IC-PD-L1 ${ }^{-}$group (figure 4B). Additionally, the $\mathrm{p} 16^{+} / \mathrm{IC}-\mathrm{PD}-$ $\mathrm{L}^{+}$group displayed a significantly better OS than the $\mathrm{p} 16^{-}$/ IC-PD-L1 ${ }^{+}$group (HR $0.14,95 \%$ CI 0.03 to $0.42 ; \mathrm{p}<0.001$ ) and the $\mathrm{p} 16^{-} / \mathrm{IC}-\mathrm{PD}-\mathrm{L}^{-}$group (HR 0.09 , 95\% CI 0.02 to $0.25 ; \mathrm{p}<0.001)$, although this was not statistically significant relative to the $\mathrm{p}^{1} 6^{+} / \mathrm{IC}-\mathrm{PD}-\mathrm{L} 1^{-}$group (HR 0.25, 95\% CI 0.05 to $1.35 ; \mathrm{p}=0.107)$.

\section{DISCUSSION}

We investigated associations between patient prognosis and p16 expression and TIMs comprising TC-PD-L1, IC-PD-L1 in stroma, and $\mathrm{CD} 8^{+}$TIL density.

We found significantly positive associations between p16 expression and TC-PD-L1 level, IC-PD-L1 level and CD8 ${ }^{+}$TIL density, which are consistent with previous reports. ${ }^{14} 15$ Based on a previous report regarding TIMs distinguished by combined TC-PD-L1 level and TILs, we evaluated combined TC-PD-L1 level $\left(<5 \%\right.$ or $\geq 5 \%$ ) with CD8 ${ }^{+}$TIL density (cut-off: median value) and demonstrated clear differences between type I TIMs in patients with $\mathrm{p} 16^{+}$tumours and type II TIMs in patients with $\mathrm{p} 16^{-}$tumours. Previous reports showed that higher rates of type I TIMs are observed in virus-related tumours, such as those associated with Epstein-Barr virus associated nasopharyngeal carcinoma and gastric cancer, compared with non-virus-related tumours ${ }^{13} 16$; these results are consistent with those in the present study involving patients with OPSCC. Additionally, virus-associated tumours elicit a more active host-antitumour immune response explained by adaptive immune resistance, where $\mathrm{T}$ cells induce expression of PD-L1 via the release of interferon (IFN) $-\gamma^{12}$ Moreover, previous studies reported that $\mathrm{CD}^{+} \mathrm{T}$ cells induce upregulated PD-L1 expression in some tumours both in vitro and in vivo. ${ }^{17}{ }^{18}$ In the present study, a higher density of $\mathrm{CD} 8^{+}$TILs in patients with OPSCC was significantly correlated with an elevated TC-PD-L1 level.

Our findings showed that among patients who had received RT, CRT or surgery as a definitive treatment, those with $\mathrm{p} 16^{+}$ OPSCC showed a significantly better survival rate compared with those with $\mathrm{p} 16^{-}$OPSCC, similar to previous reports (online supplementary figure S1). Univariate analysis demonstrated that patients with higher CD8 ${ }^{+}$TIL density or IC-PD-L1 level displayed significantly better DFS and OS. Furthermore, multivariate analyses revealed IC-PD-L1 level as a significant independent prognostic factor. Fukushima et al $^{15}$ reported that in patients who had received CRT, brachytherapy, or RT, IC-PD-L1 level was an independent factor of OS but not DFS. Additionally, Kim et $a l^{19}$ reported that IC-PD-L1 but not TC-PD-L1 is a favourable prognostic marker for patients with head and neck cancer treated with surgery. ${ }^{19}$ Although the patient cohort enrolled in our study had received surgery, CRT or RT as definitive treatment with heterogeneous effects, patients (treated with either surgery: Aor CRT/RT: B)) displaying an elevated IC-PD-L1 level showed significantly more favourable OS (online supplementary figure S2). Previous studies assessing the prognostic role of TC-PD-L1 level in various tumours reported that higher TC-PD-L1 levels were predictive of favourable outcomes in nasopharyngeal carcinoma, laryngeal cancer, and breast cancer, ${ }^{10162021}$ whereas other studies presented more controversial results. ${ }^{22-24}$ A meta-analysis by Wang et $a l^{25}$ concerning the significance of PD-L1 expression suggested a correlation between PD-L1 overexpression and worse OS in patients with solid tumours, although this correlation differed according to tumour type. ${ }^{25}$

These different results might be explained by the mechanisms associated with TC-PD-L1, which is capable of distinguishing innate expression driven by signalling pathways, such as the phosphoinositide 3 kinase (PI3K)/AKT or mitogen-activated protein kinase/extracellular-signalling regulated kinase (ERK) pathways, from adaptive expression induced by immune infiltrating cells. ${ }^{26}$ Regarding adaptive immune resistance, when tumour-infiltrating 
Table 2 Univariate and multivariate analyses of clinicopathological factors associated with DFS and OS

\begin{tabular}{|c|c|c|c|c|c|}
\hline \multirow[b]{4}{*}{ Characteristics } & \multirow[b]{4}{*}{$\mathbf{N}$} & \multicolumn{2}{|l|}{ DFS } & \multicolumn{2}{|l|}{ OS } \\
\hline & & Univariate & Multivariate & Univariate & Multivariate \\
\hline & & $P$ value & $P$ value & $P$ value & $P$ value \\
\hline & & $\mathrm{HR}(95 \% \mathrm{CI})$ & HR $(95 \% \mathrm{Cl})$ & HR $(95 \% \mathrm{Cl})$ & HR $(95 \% \mathrm{CI})$ \\
\hline \multicolumn{6}{|l|}{ Age (years) } \\
\hline$<63$ & 62 & 0.747 & & 0.89 & \\
\hline$\geq 63$ & 75 & $1.09(0.65$ to 1.84$)$ & & $0.96(0.54$ to 1.70$)$ & \\
\hline \multicolumn{6}{|l|}{ Sex } \\
\hline Male & 113 & 0.548 & & 0.635 & \\
\hline Female & 24 & 1.24 (0.64 to 2.69$)$ & & 1.20 (0.59 to 2.75$)$ & \\
\hline \multicolumn{6}{|l|}{ Differentiation } \\
\hline Well or moderately & 116 & 0.209 & & 0.223 & \\
\hline Poorly & 21 & $1.66(0.77$ to 4.31$)$ & & $1.71(0.74$ to 4.93$)$ & \\
\hline \multicolumn{6}{|l|}{ T classification } \\
\hline $\mathrm{T} 1$ or $\mathrm{T} 2$ & 78 & 0.165 & & 0.361 & \\
\hline T3 or T4 & 59 & $0.69(0.42$ to 1.16$)$ & & $0.77(0.44$ to 1.35$)$ & \\
\hline \multicolumn{6}{|l|}{ N classification } \\
\hline N0-1 & 62 & 0.45 & & 0.999 & \\
\hline N2-3 & 75 & 1.21 (0.73 to 2.03$)$ & & $1.00(0.57$ to 1.75$)$ & \\
\hline \multicolumn{6}{|l|}{ p16 } \\
\hline Positive & 59 & $<0.001^{*}$ & & $<0.001^{*}$ & \\
\hline Negative & 78 & $0.24(0.12$ to 0.46$)$ & & $0.16(0.06$ to 0.37$)$ & \\
\hline \multicolumn{6}{|l|}{ Definitive treatment } \\
\hline Surgery & 53 & 0.775 & & 0.297 & \\
\hline CRT or RT & 84 & 0.92 (0.55 to 1.55$)$ & & $0.73(0.40$ to 1.31$)$ & \\
\hline \multicolumn{6}{|l|}{ TC-PD-L1 } \\
\hline Positive & 81 & 0.08 & & ${ }^{\star} 0.036$ & 0.808 \\
\hline Negative & 56 & $0.63(0.37$ to 1.06$)$ & & $0.54(0.31$ to 0.96$)$ & 0.92 (0.48 to 1.76$)$ \\
\hline \multicolumn{6}{|l|}{ IC-PD-L1 } \\
\hline Positive & 83 & $0.008^{*}$ & $0.036^{*}$ & $<0.001^{*}$ & $0.010^{*}$ \\
\hline Negative & 54 & $0.50(0.29$ to 0.83$)$ & $0.56(0.33$ to 0.96$)$ & $0.36(0.20$ to 0.65$)$ & $0.43(0.22$ to 0.82$)$ \\
\hline \multicolumn{6}{|l|}{ CD8 } \\
\hline High ( $\geq 18.6)$ & 69 & $0.024^{*}$ & 0.121 & $0.011^{*}$ & 0.119 \\
\hline Low $(<18.6)$ & 68 & $0.54(0.32$ to 0.92$)$ & $0.64(0.37$ to 1.12$)$ & 0.47 (0.25 to 0.84$)$ & 0.61 (0.31 to 1.13$)$ \\
\hline
\end{tabular}

Significant differences were evaluated using a Cox proportional hazards model.

CRT, chemoradiotherapy; DFS, disease-free survival; IC-PD-L1, programmed death ligand 1 on immune cells; OS, overall survival; RT, radiotherapy; TC-PD-L1, programmed death ligand 1 on tumour cells.

T cells encounter tumour cells, they secrete IFN- $\gamma$, resulting in the upregulated expression of PD-L1 on tumour cells and infiltrating immune cells around the tumour cells, and subsequent exhaustion of cytotoxic TILs by the PD-1/PD-L1 axis. Therefore, PD-L1 expression might represent a marker of an active host-antitumour immune response. However, PD-L1 expression upregulated by oncogenic signalling, such as via the PI3K/AKT or MAPK/ERK pathways, is not involved in PD-L1 expression on immune cells; therefore, elevated IC-PD-L1 levels in the TIM indicates a favourable host immune response to tumours and might be a more favourable biomarker for prognosis of patients with OPSCC.

To investigate the prognostic role of p16 and IC-PD-L1 level, we classified patients into four groups based on p16 and IC-PD-L1 status, because our multivariate analyses showed IC-PD-L1 level to be an independent prognostic factor. Fukushima et al ${ }^{15}$ reported that $\mathrm{p} 16^{+} / \mathrm{IC}-\mathrm{PD}-\mathrm{L} 1^{\text {high }}$ patients displayed a favourable OS rate, whereas $\mathrm{p} 16^{-} / \mathrm{IC}-\mathrm{PD}-\mathrm{L} 1^{\text {low }}$ patients displayed an unfavourable OS rate. ${ }^{15}$ These findings were consistent with our OS-related results, and we also demonstrated that $\mathrm{p} 16^{+} /$
IC-PD-L $1^{\text {high }}$ or $\mathrm{p} 16^{-} / \mathrm{IC}-\mathrm{PD}-\mathrm{L} 1^{\text {low }}$ patients displayed better and worse DFS, respectively.

In addition to the prognostic role of the IC-PD-L1 level, several studies reported elevated PD-L1 expression might be predictive of the response to a PD-1/PD-L1 inhibitor. ${ }^{27-29}$ These findings suggest that assessment of IC-PD-L1 level by IHC might be predictive of therapeutic outcomes for patients with OPSCC receiving a PD-1/PD-L1 inhibitor, as well as provide prognostic information concerning patients treated with a definitive treatment.

Our study has several limitations. First, we used a retrospective cohort involving a small number of patients. Second, some clinical characteristics, such as definitive treatment, in the enrolled patients were heterogeneous. Third, evaluation of TC-PD-L1 or IC-PD-L1 level and CD8 ${ }^{+}$TIL density might have been hampered by intratumoural heterogeneity. Therefore, future investigations and validations using prospective studies with a larger patient sample size are required.

In conclusion, we demonstrated that IC-PD-L1 level, but not TC-PD-L1 level, represents a useful prognostic biomarker in 


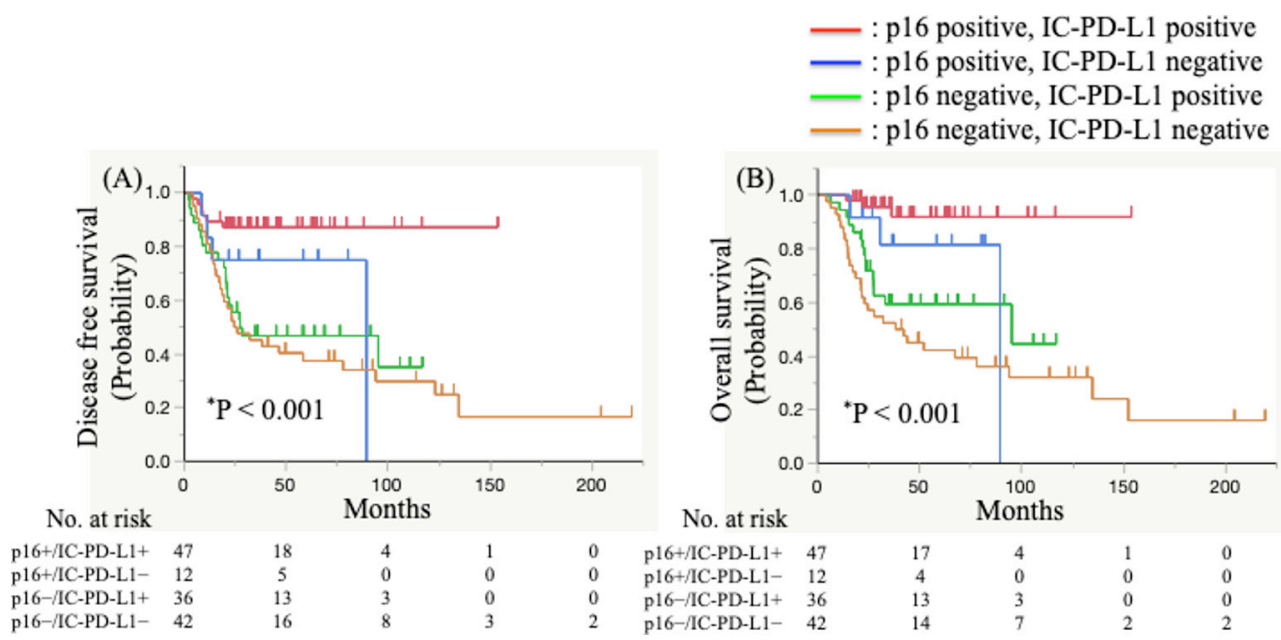

Figure 4 Kaplan-Meier analysis of the disease-free survival $(A)$ and overall survival of $(B)$ of patients with advanced oropharyngeal squamous cell carcinoma. $\mathrm{p}^{+} 6^{+}$or $\mathrm{p} 16^{-}$status combined with programmed death ligand 1 (PD-L1) ${ }^{+}$or PD-L1 ${ }^{-}$immune cells (IC-PD-L1). Significant differences were evaluated using a log-rank test.

additional to p16 expression in patients with OPSCC receiving a definitive treatment. Additionally, we propose that co-assessment of the status of p16 and IC-PD-L1 offers greater prognostic potential compared with evaluating each factor alone in patients with OPSCC.

\section{Take home messages}

- Programmed death ligand 1 (PD-L1) expression level on immune cells is an independent and significant predictive factor of disease-free survival and overall survival in patients with oropharyngeal cancer.

- PD-L1 expression level on immune cells represents a useful prognostic biomarker in addition to 16 expression in patients with oropharyngeal cancer.

- Co-assessment of the status of p16 and PD-L1 expression on immune cells offers greater prognostic potential compared with evaluating each factor alone in patients with oropharyngeal cancer.

\section{Handling editor Runjan Chetty.}

Acknowledgements We wish to express our gratitude to the Head and Neck Oncology team and the Radiation Oncology team for their kind support throughout the study.

Contributors Substantial contributions to the conception or design of the work: TO. The acquisition, analysis, and interpretation of data for the work: FS, TO, AK, TK, HT, KS, TK, JA, HU and HY. Drafting the work: FS. Revising the work critically for important intellectual content: TO, AK, TK, JA, Dr. HU and HY. Final approval of the version to be published: TO, AK, TK, HT, KS, TK, JA, HU and HY. Agreement to be accountable for all aspects of the work in ensuring that questions related to the accuracy or integrity of any part of the work are appropriately investigated and resolved: TO, AK, TK, HT, KS, TK, JA, HU and HY.

Funding The authors have not declared a specific grant for this research from any funding agency in the public, commercial or not-for-profit sectors.

Competing interests None declared.

Patient consent for publication Not required.

Provenance and peer review Not commissioned; internally peer reviewed.

Data availability statement Data are available in a public, open access repository. There are no data in this work. Data are available upon reasonable request. Data may be obtained from a third party and are not publicly available. No data are available. All data relevant to the study are included in the article or uploaded as supplementary information.
Open access This is an open access article distributed in accordance with the Creative Commons Attribution Non Commercial (CC BY-NC 4.0) license, which permits others to distribute, remix, adapt, build upon this work non-commercially, and license their derivative works on different terms, provided the original work is properly cited, appropriate credit is given, any changes made indicated, and the use is non-commercial. See: http://creativecommons.org/licenses/by-nc/4.0/.

\section{REFERENCES}

1 Ang KK, Harris J, Wheeler R, et al. Human papillomavirus and survival of patients with oropharyngeal cancer. N Engl J Med Overseas Ed 2010;363:24-35.

2 Horne ZD, Glaser SM, Vargo JA, et al. Confirmation of proposed human papillomavirus risk-adapted staging according to AJCC/UICC TNM criteria for positive oropharyngeal carcinomas. Cancer 2016;122:2021-30.

3 Matlung SE, Wilhelmina van Kempen PM, Bovenschen $\mathrm{N}$, et al. Differences in T-cell infiltrates and survival between HPV + and HPV- oropharyngeal squamous cell carcinoma. Future Science OA 2016:2.

4 Fridman WH, Zitvogel L, Sautès-Fridman C, et al. The immune contexture in cancer prognosis and treatment. Nat Rev Clin Oncol 2017;14:717-34.

5 Pardoll DM. The blockade of immune checkpoints in cancer immunotherapy. Nat Rev Cancer 2012;12:252-64.

6 De Meulenaere A, Vermassen T, Aspeslagh S, et al. Tumor PD-L1 status and CD8 ${ }^{+}$ tumor-infiltrating $T$ cells: markers of improved prognosis in oropharyngeal cancer. Oncotarget 2017:8:80443-52.

7 Herbst RS, Soria J-C, Kowanetz M, et al. Predictive correlates of response to the antiPD-L1 antibody MPDL3280A in cancer patients. Nature 2014;515:563-7.

8 Vermorken JB, Psyrri A, Mesía R, et al. Impact of tumor HPV status on outcome in patients with recurrent and/or metastatic squamous cell carcinoma of the head and neck receiving chemotherapy with or without cetuximab: retrospective analysis of the phase III extreme trial. Ann Oncol 2014;25:801-7.

9 Ukpo OC, Thorstad WL, Lewis JS. B7-H1 expression model for immune evasion in human papillomavirus-related oropharyngeal squamous cell carcinoma. Head and Neck Pathol 2013;7:113-21.

10 Zhu Q, Cai M-Y, Chen C-L, et al. Tumor cells PD-L1 expression as a favorable prognosis factor in nasopharyngeal carcinoma patients with pre-existing intratumor-infiltrating lymphocytes. Oncolmmunology 2017;6:e1312240.

11 Sobin LH, Gospodarowicz MK, Wittekind CH. TNM classification of malignant tumours. 7th edn. New York: John Wiley \& Sons, 2009: 30-8.

12 Teng MWL, Ngiow SF, Ribas A, et al. Classifying cancers based on T-cell infiltration and PD-L1. Cancer Res 2015;75:2139-45.

13 Koh J, Ock C-Y, Kim JW, et al. Clinicopathologic implications of immune classification by PD-L1 expression and CD8-positive tumor-infiltrating lymphocytes in stage II and III gastric cancer patients. Oncotarget 2017;8:26356-67.

14 Badoual C, Hans S, Merillon N, et al. PD-1-Expressing tumor-infiltrating T cells are a favorable prognostic biomarker in HPV-associated head and neck cancer. Cancer Research 2013:73:128-38.

15 Fukushima Y, Someya M, Nakata K, et al. Influence of PD-L1 expression in immune cells on the response to radiation therapy in patients with oropharyngeal squamous cell carcinoma. Radiotherapy and Oncology 2018;129:409-14.

16 Ono T, Azuma K, Kawahara A, et al. Prognostic stratification of patients with nasopharyngeal carcinoma based on tumor immune microenvironment. Head \& Neck 2018;40:2007-19. 
17 Tumeh PC, Harview CL, Yearley JH, et al. PD-1 blockade induces responses by inhibiting adaptive immune resistance. Nature 2014;515:568-71.

18 Sfanos KS, Bruno TC, Meeker AK, et al. Human prostate-infiltrating CD8 ${ }^{+} \mathrm{T}$ lymphocytes are oligoclonal and PD-1 ${ }^{+}$. Prostate 2009;69:1694-703.

19 Kim HR, Ha S-J, Hong MH, et al. PD-L1 expression on immune cells, but not on tumor cells, is a favorable prognostic factor for head and neck cancer patients. Sci Rep 2016;6.

20 Park IH, Kong S-Y, Ro JY, et al. Prognostic implications of tumor-infiltrating lymphocytes in association with programmed death ligand 1 expression in early-stage breast cancer. Clin Breast Cancer 2016;16:51-8.

21 Vassilakopoulou M, Avgeris M, Velcheti V, et al. Evaluation of PD-L1 expression and associated tumor-infiltrating lymphocytes in laryngeal squamous cell carcinoma. Clinical Cancer Research 2016:22:704-13.

22 CY M, Huang JA, Chen Y, et al. High expression of PD-L1 in lung cancer may contribute to poor prognosis and tumor cells immune escape through suppressing tumor infiltrating dendritic cells maturation. Med Oncol 2011;28:682-8.

23 Chen Y-bin, Mu C-Y, Huang J-A. Clinical significance of programmed death-1 ligand-1 expression in patients with non-small cell lung cancer: a 5-year-follow-up study. Tumori Journal 2012:98:751-5.
24 Shin S-J, Jeon YK, Kim P-J, et al. Clinicopathologic analysis of PD-L1 and PD-L2 expression in renal cell carcinoma: association with oncogenic proteins status. Ann Surg Oncol 2016;23:694-702.

25 Wang Q, Liu F, Liu L. Prognostic significance of PD-L1 in solid tumor: an updated meta-analysis. Medicine 2017;96:e6369.

26 Topalian SL, Taube JM, Anders RA, et al. Mechanism-driven biomarkers to guide immune checkpoint blockade in cancer therapy. Nat Rev Cancer 2016:16:275-87.

27 Massard C, Gordon MS, Sharma S, et al. Safety and efficacy of Durvalumab (MEDI4736), an Anti-Programmed cell death ligand-1 immune checkpoint inhibitor, in patients with advanced urothelial bladder cancer. JCO 2016:34:3119-25.

28 Chow LQM, Haddad R, Gupta S, et al. Antitumor activity of pembrolizumab in Biomarker-Unselected patients with recurrent and/or metastatic head and neck squamous cell carcinoma: results from the phase Ib KEYNOTE-012 expansion cohort. JCO 2016;34:3838-45.

29 Ferris RL, Blumenschein G, Harrington K, et al. Abstract CT021: Tumor-associated immune cell PD-L1 expression and peripheral immune profiling: analyses from CheckMate 141. Cancer Research 2017;77(13 Supplement):CT021. 